reading the scientific literature. What some of us are really 'fearful' of, is dental professionals and government officials who feel it is more important to defend this practice rather than to protect the health of citizens from this toxic substance.

P. Connett, Retired professor of chemistry, Senior Adviser to the Fluoride Action Network

1. Reekie D. Fear of fluoride. Br Dent J 2017; 222: 16-18.

DOI: 10.1038/sj.bdj.2017.198

\section{Like a knee in the gut}

Sir, having promoted fluoride ingestion for the first 25 years of dental practice, I am sympathetic to Reekie's dilemma regarding education of the sceptical patient. ${ }^{1}$ Listening to my 'fearful' patients, I finally read the research for myself. The evidence is like a knee in the gut. Many are ingesting too much fluoride. Benefit is not supported by good science. The evidence of serious risk is rapidly growing. My dental and public health professions would create less fear if we have balanced science based answers.

We should warn patients not to swallow toothpaste, use a tiny smear on a brush for children, and pregnant mothers to be especially careful not to swallow fluoride or fluoride products. Carefully instructing our patients with balanced evidence will raise their confidence in our profession and reduce their fear.

W. Osmunson,

Fluoride Action Network, Director

1. Reekie D. Fear of fluoride. Br Dent J 2017; 222: 16-18.

DOI: 10.1038/sj.bdj.2017.199

\section{English language}

\section{An Indian view}

Sir, English, the universal language on the Internet, has created a global village, brought researchers to the same platform and caused a 'brain drain' from India. The present trend of low English proficiency among dental graduates is a cause of concern, not only when they practise in India but also when they migrate. For primary education, private schools prefer English as medium of instruction while public schools use regional languages; however, centres of higher education follow English. Public school-bred students have to read and listen in English, think and understand in their mother tongue and reproduce the concept in English for assessments. The student often grasps the concept when explained in a regional language but is unable to translate the same in English. Reference books are available only in English and not all scientific terms can be 'Indianised'.

At postgraduate level reference books, journals, publications and conference presentations require proficient English where incompetency can be a handicap. We need to act-in-time to contain the scenario. Forcing a foreign language for higher education can be argued as a form of 'linguistic dictatorship' or 'mother tongue slavery', but English is no longer a foreign language in India. We suggest forming committees with representatives from the Dental Council of India, dental schools, a few bright students, recent graduates and educators to analyse the situation; encourage compulsory and regular use of contemporary English and medical dictionaries and introduce a compulsory six month pre-dental English course; recruit good bilingual faculty; conduct group activities like English reading and promote self-assessment among students.

J. George, Lucknow, India

D. Mandhyan, Bhairwah, Nepal

U. K. Jha, Hazaribagh, India DOI: $10.1038 /$ sj.bdj.2017.200

\section{Referrals}

\section{An orthodontic opinion}

Sir, we write regarding the letter Impacted canines $^{1}$ by M. Wardle. As the authors of a Cochrane review in this area, ${ }^{2}$ we urge general dental practitioners NOT to remove the primary canine without an orthodontic opinion. There is evidence that removal of the primary canine might help in some patients; however, other aspects, such as space available and severity of displacement of the permanent canine, are very important considerations. Other concerns include the condition of the crown and root of the primary canine; some have excellent roots and a good long-term prognosis. Extracting such a primary canine in a patient that is not suitable for lengthy treatment with fixed appliances (due to either poor oral hygiene or motivation) might leave the patient with an unsightly gap, when they could have had their primary canine in situ for decades. We believe that the majority of specialist orthodontists, despite long waiting lists, will triage their referrals and see a patient sooner, if there is good reason.

P. Benson, N. Parkin, Sheffield

Wardle M. Impacted canines. Br Dent J 2017: 222: 2

2. Parkin N, Furness $S$, Shah A et al. Extraction of primary (baby) teeth for unerupted palatally displaced permanent canine teeth in children. Cochrane Database Syst Rev 2012; 12: CD004621.

DOI: 10.1038/sj.bdj.2017.201

\section{A utopian aim}

Sir, I read with interest P. Raftery's letter regarding apicectomy. ${ }^{1}$ I was intrigued by his contention that specialist endodontists be considered for NHS apicectomy referrals.

His utopian aim for a service which can provide the staffing, ultrasonic equipment and magnification to boot is commendable, albeit for an increasingly uncommon procedure.

As a staff member in a maxillofacial unit which can provide apicectomies, my colleagues and I are cognisant of the 'gold standards'. Often in our service the majority of the referrals do not meet the criteria for an apicectomy. As a result we advise the patient on the myriad other treatment options, rather than blindly proceed with a hopeless apicectomy using our 'stone age non-ultrasonic implements'

Our department is paid $£ 134$ per apicectomy by the NHS. If Mr Raftery can usher in a revolution in NHS apicectomy treatment for this fee he is gladly welcome to it.

D. Shiels, Chesterfield

1. Raftery P. Referrals: Apicectomy. Br Dent J 2017; 222: 2.

DOI: 10.1038/sj.bdj.2017.202

\section{Social media}

\section{Undermining trust}

Sir, I would like to comment on Dr Ilona Johnson's insightful response to my letter. ${ }^{1}$ I accept most of her points but I am concerned about part of Dr Johnson's conclusion. The suggestion was that dental students/professionals should manage their public image, '. .. in order to engender and maintain trust in our profession. Presumably, the concern is that if people saw how they actually behaved they might not trust them. Notwithstanding GDC guidance, this seems open to a charge of hypocrisy and actively undermines trust.

P. Affleck, Leeds

1. P. Affleck. Social media: Professionalism. Br Dent $J$ 2017; 222: 68-69.

DOI: $10.1038 /$ sj.bdj.2017.203 